\title{
A COMPARATIVE STUDY OF BENZYLPENICILLIN VERSUS CEFTRIAXONE IN THE TREATMENT OF ADULT PYOGENIC MENINGITIS
}

\author{
WAZIB A ${ }^{1}$, HOSSAIN MZ2 ${ }^{2}$ HASAN R ${ }^{3}$, ALAM MB ${ }^{4}$

\begin{abstract}
This prospective study was conducted in Dhaka Medical College Hospital during July 2006 to June 2007. 100 patients were included in the study among which forty seven received benzylpenicillin and fifty three was treated with ceftriaxone. The result of this study showed that mortality was similar in both groups but ceftriaxone had better outcome regarding duration of clinical features and hospital-stay.
\end{abstract} \\ Abstract
}

Key words : pyogenic meningitis, benzylpenicillin, ceftriaxone.

J Dhaka Med Coll. 2008; 17(2) : 59-61.

\section{Introduction:}

Pyogenic meningitis is the pyogenic infection of subarachnoid space. ${ }^{1}$ The mortality and morbidity is significant despite the availability of an increasing range of antibiotics. The diagnosis is made by clinical triad of fever, headache and neck rigidity along with a positive CSF study.$^{2}$ It is a medical emergency and rapid diagnosis and therapeutic interventions can be life saving. Empirical antibiotic therapy should be initiated without delay as soon as the diagnosis of bacterial meningitis is established clinically. ${ }^{2}$ The most common causes of pyogenic meningitis in adult are Streptococcus pneumoniae, Neisseria meningitides and Haemophilus influenzae. ${ }^{3}$ Ceftriaxone is a third generation cephalosporin that has the advantage of less number of daily doses and lesser chance of hypersensitivity reaction but proves costly for a good number of patients who are economically not very solvent. 4, 5 Benzylepenicilline is a penicillin that needs frequent doses and has a higher risk of hypersensitivity reaction. 4,5 It is cheaper than ceftriaxone, affordable to most of the patients of the lower socio-economic stratum. The purpose of the study was to compare the outcome of adult pyogenic meningitis patients treated with benzylpenicillin and ceftriaxone.

\section{Materials and Methods:}

This was a prospective interventional study. The sample size was 100 patients diagnosed as pyogenic meningitis who were e" 14 years of age and had duration of illness d" 7 days. The diagnosis was made on the basis of fever, deteriorated level of consciousness, signs of meningeal irritation along with certain features of CSF - hazyness, neutrophilic pleocytosis, high protein, low glucose with or without isolation of bacteria by Microscopy or culture. Patients under 14 years, with duration of illness $>7$ days prior admission and who received either benzylpenicillin or ceftriaxone before admission were not enrolled in the study. Patients with lateralizing signs on admission were also excluded as there was possibility of brain abscess or meningitis complicated with cerebral infarction.

Permission from the hospital authority was taken before starting the study. All patients or their legally authorized attendants gave informed written consent before enrollment. All the information was collected in a predesigned case record form. The treatment provided by respective units was never modified in any part for the sake of this study.

1. Clinical Pathologist, Department of Microbiology, Dhaka Medical College, Dhaka

2. Assistant Professor, Department of Medicine, Dhaka Medical College \& Hospital, Dhaka

3. Medical Officer, Department of Medicine, Chittagong Medical College Hospital, Chittagong

4. Associate Professor, Department of Medicine, Dhaka Medical College \& Hospital, Dhaka

Correspondence : Dr. Amit Wazib 
After admission, a short relevant history was taken, emergency was met up and patients were resuscitated according to their presentation by respective units. Then a detailed medical history was obtained regarding the presenting complaints, the mode of onset, its chronological development, history of previous medication and past illness.

A thorough physical examination was done after taking a history. Level of consciousness was assessed and a careful search was made for signs of meningeal irritation. Any rash, focal neurological sign or any form of infection anywhere in the body were also looked for. Other systems were also examined to detect any associated disease. Lumbar puncture was done by the respective units immediately after exclusion of raised ICP. The appearance of CSF was observed at the time of puncture. CSF was sent for cytological, biochemical and microbiological examination.

Treatment with antibiotic was started as soon as the clinical diagnosis of bacterial meningitis was done. Forty seven patients received intravenous benzylpenicillin 4 million units 4 hourly, after a negative intradermal test dose. Twenty four (51.06 percent) got adjunctive intravenous dexamethasone $10 \mathrm{mg}$ every 6 hours for 4 days. 53 patients received intravenous ceftriaxone $2 \mathrm{~g} 12$ hourly. Adjuvant dexamethasone was given in 27 patients $(50.94$ percent).

All other supportive measures were taken according to the need of individual cases.
The patients were followed-up regularly with special emphasis on temperature, signs of meningeal irritation and level of consciousness. The outcome was assessed on the basis of temperature, level of consciousness, signs of meningeal irritation and duration of stay in hospital. Statistical methods (t-test and Fisher's exact test) were applied to get a result using SPSS.

\section{Results:}

The study shows that pyogenic meningitis is more common in younger age group and male. Bacteria was isolated in forty eight percent patients of which Neisseria meningitides topped among the causative organisms followed by Streptococcus pneumoniae and Haemophilus influenzae. No organism could be detected in majority of the cases.

Mean duration of fever was 5.75 days in benzylpenicillin group and 3.86 days in ceftriaxone group. Mean duration of neck rigidity was 4.82 days and 3.14 days respectively. Mean duration of altered consciousness was 2.89 days and 2.38 days in the respective groups. Mean duration of hospital stay was 8.92 days and 6.48 days respectively. There was statistically significant difference in these parameters between the two groups ( $p<0.01)$. Mortality (4 in both groups) did not differ significantly between the two groups ( $\mathrm{p}>0.05)$. (Table I)

No clinically significant anaphylactic reaction was observed in any patient.

Table-I

Clinical parameters in pyogenic meningitis

\begin{tabular}{lccc}
\hline Parameter & Benzylpenicillin group & Ceftriaxone group & P value \\
\hline Duration of fever (days) ( $\pm \mathrm{SD})$ & $5.75 \pm 2$ & $3.86 \pm 2.4$ & $<0.01^{*}$ \\
Duration of neck rigidity (days) (SD) & $4.82 \pm 1.8$ & $3.14 \pm 1.9$ & $<0.01^{*}$ \\
Duration of altered consciousness (days) (SD) & $2.89 \pm 1.9$ & $2.38 \pm 1.2$ & $<0.01^{*}$ \\
Duration of hospital stay (days) (SD) & $8.92 \pm 2.8$ & $6.48 \pm 2.8$ & $<0.01^{*}$ \\
Number of deaths & 4 & 4 & $>0.05^{*}$ \\
\hline * t-test & & & \\
- Fisher's exact test & &
\end{tabular}




\section{Discussion:}

This study represents a small effort to compare the outcome in pyogenic meningitis in adults treated with either benzylpenicillin or ceftriaxone. The baseline characteristics of the two groups were nearly similar.

The study shows that pyogenic meningitis is more common in younger age group and male which is consistent with the study of Dube and Shenderov. ${ }^{6}$

Gram staining and culture of CSF identified bacteria in only 48 percent patients of which Neisseria meningitides dominated which was consistent with the study of Schuchat, Robinson and Wenger. ${ }^{7}$ Bacteria could not be isolated in majority of cases may be due to prior antibiotic therapy or inadequate isolation technique.

No clinically significant anaphylactic reaction was observed in any patient which is consistent with the study of Pelger, Galler, Roberts, Thomas and Woodhouse. ${ }^{8}$

The result of this study showed that treatment with ceftriaxone had better outcome regarding duration of clinical features (fever and level of consciousness) which is consistent with the study of Prasad, Singhal, Jain and Gupta. ${ }^{9}$

The duration of hospital-stay is also significantly less in patients treated with ceftriaxone which is consistent with the study of Chaudhury, Martin, Kennedy, et al. ${ }^{10}$

But there was no significant difference in mortality which differs from the result of the study of Chaudhury, Martin and Kennedy. ${ }^{10}$ But it was consistent with that of the study of Pelger, Galler, Roberts, Thomas and Woodhouse. ${ }^{8}$

This study was based on clinical parameters only. The actual antimicrobial sensitivity result was not considered. The number of study population was small. So a study containing greater number of patients over a wide range of time considering both clinical parameters and antimicrobial sensitivity result is recommended.

\section{Conclusion:}

Pyogenic meningitis is a medical emergency and requires early antibiotic therapy before laboratory isolation of microorganisms and antimicrobial sensitivity reports are available. Ceftriaxone can be used as the initial antibiotic of choice for adult pyogenic meningitis patients who can afford. Benzylpenicillin can be used as an effective alternative for the poor patients who comprise the majority of cases of adult pyogenic meningitis. But antibiotic can be changed in the course of treatment according to clinical response and if available, culturesensitivity result.

\section{Acknowledgement:}

We are very much grateful to Prof. A K M Rafique Uddin, the then Head, Department of Medicine, Dhaka Medical College for his kind permission and patience guidance during this study. We must thank Dr. Md. Shafiqul Bari, the then Registar, Department of Medicine, Dhaka Medical College for his full co-operation and close supervision.

\section{References:}

1. Roos KL, Tyler LK. Meningitis, encephalitis, brain abscess and other Suppurative Infections. In: Kasper DL, Fauci AS, Longo DL, Braunwald E, Jameson JL, Hauser SL, Hausern SL, Longo DL, Jameson JL, eds. Harrison's Principles of Internal Medicine, $16^{\text {th }}$ ed. USA: The McGraw- Hill Companies; 2005: p. 2471-89.

2. Swartz MN. Bacterial meningitis. In: Goldman, Bennett, eds. Cecil Textbook of Medicine, $21^{\text {st }}$ ed. UK: WB Saunders Company; 2001: p. 1645-54.

3. Allen CMC, Lueck CJ. Neurological diseases. In: Haslett C, Chilvers ER, Boon NA, Colledge NR, Hunter JAA, eds. Davidson's Principles and Practice of Medicine, $19^{\text {th }}$ ed. Edinburgh: Churchill Livingstone; 2002: p. 1193-94.

4. Chambers HF, Hadley WK, Jawetz E. Beta lactam antibiotics and other inhibitors of cell wall synthesis. In: Katzung, eds. Basic and Clinical Pharmacology, $7^{\text {th }}$ ed. New York: Lange Medical Books, The McGrawHill Companies, 1998: p. 725-35.

5. Laurence DR, Benell PN, Broen MJ. Antibacterial drugs. In: Clinical Pharmacology $8^{\text {th }}$ ed. Edinburgh: Churchill Livingstone, 1997: p. 198-204.

6. Dube SD, Shenderov BA. Incidence and pattern of bacterial meningitis in Lusaka. Cent Afr J Med. 1983; 5: 100-3.

7. Schuchat A, Robinson K, Wenger JD et al. Bacterial meningitis in the United states in 1995. N Engl J Med. 1997; 337: 970.

8. Pelger RE, Galler L, Roberts S, Thomas M. Three day of intravenous benzylpenicillin treatment of acute bacterial meningitis in adult. Available at http:www. Journals.uchicago.edu/doi/abs / 10.1086/377203. Accessed 12 May, 2008.

9. Prasad, Singhal T, Jain N, Gupta PK. Third generation cephalosporin versus conventional antibiotics for treating acute bacterial meningitis. Available at http://www.ichrc.org/pdf/ meningmeningo.pdf . Accessed 10 May, 2010.

10. Chaudhury A, Martin PM, Kennedy PGE, et al. EFNS guideline on the management of community acquired bacterial meningitis. European J Neurol. 2008; 15: 649-59. 